\title{
REVIEWS
}

\section{Review of the role of non-invasive ventilation in the emergency department}

\author{
Anthony M Cross
}

One of the first descriptions of a "pulmonary plus pressure machine" in 1936 describes varying success in the treatment of cardiac asthma and bronchial asthma. ${ }^{1}$ The author describes how an Electrolux or Hoover vacuum cleaner can be used to supply air at positive pressure and wisely cautions that "the machine should be run for some minutes first of all to get rid of the dust".

The aim of this article is to review the effects of non-invasive ventilation in acute respiratory failure, the evidence for its use in an emergency setting, and make some recommendations concerning its optimal use.

\section{Pathophysiological effects of non-invasive ventilation}

EFFECTS ON THE RESPIRATORY SYSTEM

Extrinsically applied positive end expiratory pressure (ePEEP) increases alveolar size and recruitment. ${ }^{2}{ }^{3}$ This expands the area available for gas exchange, reduces intrapulmonary shunt, improves lung compliance, and decreases the work of breathing. ${ }^{3-6}$ It acts to negate the effects of intrinsic PEEP (iPEEP), which is the cause of dynamic airway compression and gas trapping. ${ }^{78}$ Ventilation is improved with beneficial effects on the alveolararterial gradient, hypercarbia and, to a lesser extent, hypoxia. ${ }^{9} 10$

Pressure support (alone or as part of bilevel positive airway pressure, BiPAP) further augments alveolar ventilation and allows some respiratory muscle rest during the inspiratory phase. $^{11}$

EFFECTS ON THE CARDIOVASCULAR SYSTEM PEEP reduces venous return to the right side of the heart. ${ }^{12}$ Left ventricular preload, transmural pressure, and relative afterload are all decreased without altering myocardial contractility. ${ }^{12-14}$ Thus, the ejection fraction improves without an increase in myocardial oxygen consumption. ${ }^{12}{ }^{15}$ It appears that those with worst ventricular dysfunction show the most significant improvement in stroke volume index with continuous positive airway pressure (CPAP). ${ }^{16}$

Overall, CPAP leads to a decrease in arterial pressure, heart rate, and rate-pressure product within 10 minutes, without exacerbation of hypotension. ${ }^{17}$
EFFECTS ON OTHER SYSTEMS

Intracranial pressure (ICP) -in patients with raised ICP there may be an increase in ICP by at least the same degree as the PEEP applied. ${ }^{18}$

Renal-PEEP causes decreased sodium excretion and urine output, possibly due to raised vena caval pressure reducing cortical blood flow. ${ }^{4}$

\section{Applying non-invasive ventilation} EQUIPMENT

There are two major options for interface between patient and machine: nasal masks and (oronasal) facemasks. Nasal masks have traditionally been used in the setting of chronic, home therapy and have also been applied to the acute setting. They offer the advantages of a smaller dead space, less claustrophobia, and the ability to utilise the mouth quickly and easily (for communication, expectoration, vomiting, and oral intake), albeit with the loss of pressure. Dyspnoeic patients, however, are typically mouth breathers and the oral route offers less resistance to gas flow. Thus, facemasks are preferable for treatment of acute respiratory failure in the emergency department.

The use of a mouthpiece has also been described ${ }^{19}$ but requires nasal occlusion and a good mouth seal making leak avoidance difficult. A full facemask has recently been developed and is reported as having advantages over other means of applying non-invasive ventilation. ${ }^{20}$

MONITORING

Monitoring of patients undergoing noninvasive ventilation should be similar to that generally used to manage patients with acute respiratory failure. Non-invasive blood pressure monitoring at intervals of 5-15 minutes, continuous electrocardiography (ECG) monitoring, ongoing pulse oximetry, assessment of respiratory rate, temperature, chest radiography, and 12 lead ECG is recommended.

Frequent arterial blood gas analysis will aid therapeutic decision making but will be limited by the means of arterial sampling employed (intermittent puncture compared with arterial line). The frequency of blood gas analysis in the major trials was quite variable; from every 30 minutes for six hours ${ }^{21}$ to at one hour, three days, and seven days. ${ }^{22}$ Blood gas analysis as 


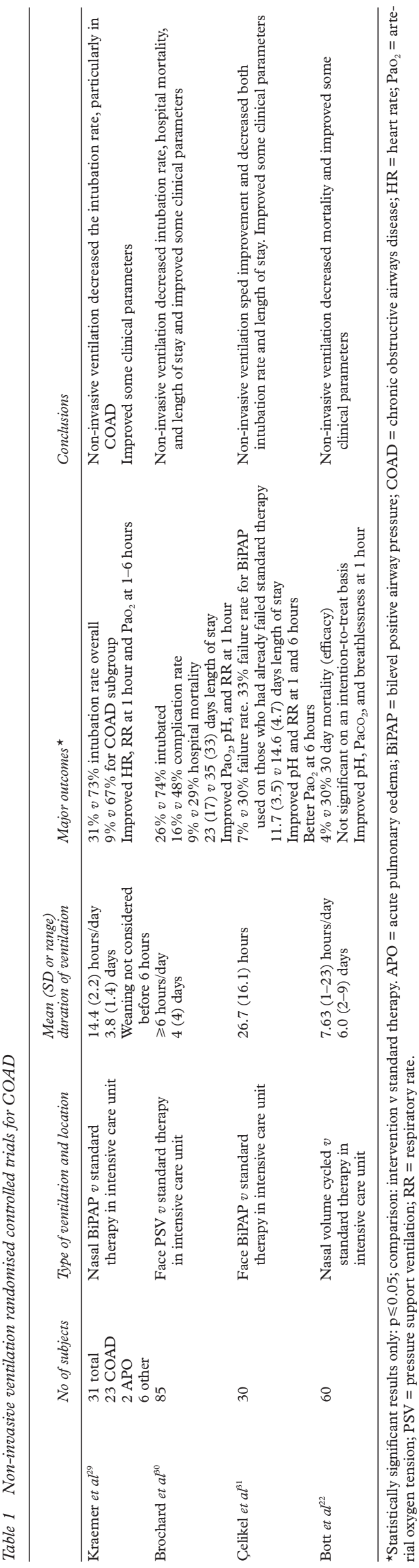

soon as practical after presentation is recommended. Additional sampling should be performed to monitor progress. Depending on the patient's condition one to two hourly sampling should be sufficient.

LEVEL OF PEEP

The goals of acute respiratory therapy should be maintenance of an arterial oxygen saturation $>90 \%$ or arterial oxygen tension $\left(\mathrm{PaO}_{2}\right)$ $>8.0 \mathrm{kPa}(>60 \mathrm{~mm} \mathrm{Hg}) .{ }^{323}$ This degree of oxygenation should be maintained during weaning from non-invasive ventilation. The optimal level of PEEP to apply is one which closely matches iPEEP. ${ }^{2425}$ Given the difficulty in measuring iPEEP in the emergency setting the most practical solution is a gradual increase in ePEEP (for example by $2.5-5.0 \mathrm{~cm} \mathrm{H}_{2} \mathrm{O}$ ) until a satisfactory response is achieved. ${ }^{324}$ It is recommended that PEEP (that is CPAP or expiratory positive airway pressure, EPAP) be started at $4-6 \mathrm{~cm} \mathrm{H}_{2} \mathrm{O}$ and inspiratory pressure (if used) at $8-14 \mathrm{~cm} \mathrm{H}_{2} \mathrm{O}^{26}$ The effect of changes in non-invasive ventilation on arterial blood gases is evident within 10-15 minutes with no further effect demonstrable at 30 minutes. ${ }^{27} 28$ This suggests incremental increases in ventilatory therapy could be applied every 15 minutes, if needed, until a satisfactory degree of oxygenation is attained. The clinician should also observe an improvement in the clinical condition within one to two hours.

\section{Evidence for the use of non-invasive} ventilation

EVIDENCE FOR USE IN OBSTRUCTIVE AIRWAYS DISEASE

There are only four randomised controlled trials comparing non-invasive ventilation with standard treatment in acute exacerbations of obstructive airways disease carried out in intensive care units (table 1). Different modes of ventilation were used in each: nasal $\mathrm{BiPAP},{ }^{29}$ facemask pressure support ventilation (no CPAP/EPAP component), ${ }^{30}$ facemask BiPAP, ${ }^{31}$ and nasal volume cycled positive pressure ventilation. $^{22}$

Two of the studies using pressure cycled ventilation $^{29}{ }^{30}$ demonstrated significantly decreased intubation rates compared with standard treatment $(1 / 11(9 \%) v 8 / 12(67 \%)$ and $11 / 43(26 \%)$ v $31 / 42(74 \%)$, respectively). The other study using pressure cycled ventilation found BiPAP to be successful (defined as improvement in gas exchange, clinical parameters, and discharge from the hospital) in 14/15 (93\%) compared with $9 / 15(60 \%)$ with standard treatment alone. ${ }^{31}$ Those who failed with standard treatment received a trial of BiPAP that was successful in $4 / 6(60 \%)$. All the studies using pressure cycled ventilation showed significant differences in some respiratory and cardiovascular parameters (respiratory rate, heart rate, $\mathrm{pH}$, and $\mathrm{PaO}_{2}$ ) after one and six hours of treatment, compared with standard treatment. There was no significant improvement in arterial carbon dioxide tension $\left(\mathrm{PaCO}_{2}\right)$ compared with standard treatment. On subsequent days there was no difference in these parameters between treatment and control 


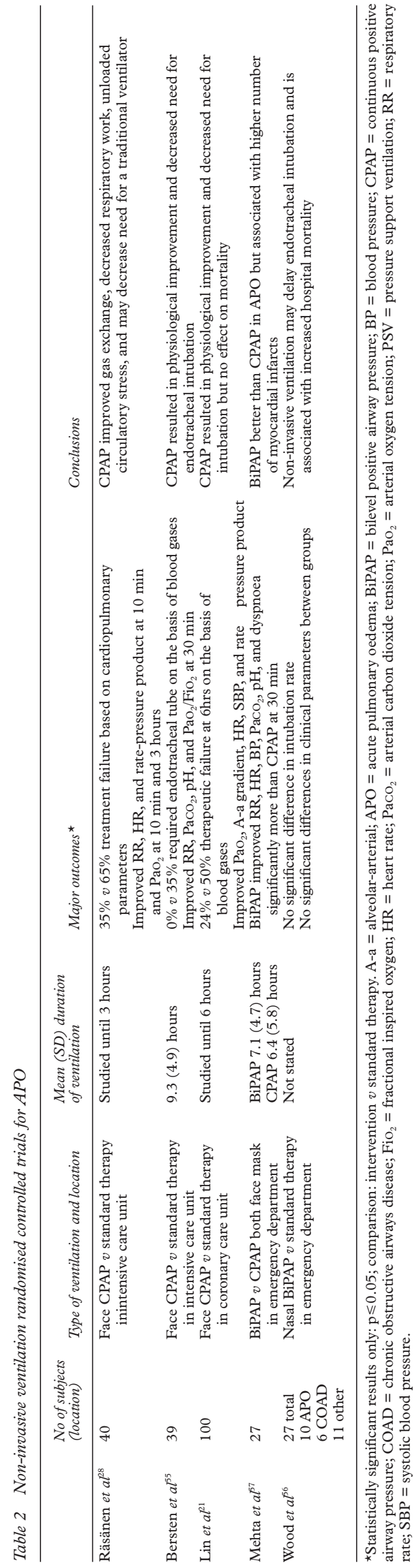

groups. The larger study, with 85 patients, had significantly reduced in-hospital mortality rates (4/43 (9\%) compared with 12/42 (29\%)), significantly decreased hospital length of stay (mean $23 v 35$ days), and fewer life threatening complications (mainly pneumonia, complicated intubations, and cardiac arrest after weaning). ${ }^{30}$

Volume cycled ventilation also demonstrated decreased mortality compared with controls $(1 / 24(4 \%)$ v 9/30 (30\%)) when looking at efficacy with respect to 30 day survival. ${ }^{22}$ However intention-to-treat 30 day mortality (3/30 $(10 \%))$ was not significantly better than in the control group. Respiratory parameters were significantly better in the treatment group at one hour ( $\mathrm{pH}, \mathrm{PaCO}_{2}$, and breathlessness) but not on days 3 or 7 .

Case series studies of patients with acute exacerbations of obstructive airways disease report effective outcomes with both $\mathrm{CPAP}^{19}{ }^{32-38}$ and $\mathrm{BiPAP}^{39-53}$ with respect to clinical parameters, arterial blood gases, and need for intubation compared with (often historical) controls and previously published data. When patients were cycled through a range of ventilatory modalities, CPAP and pressure support ventilation were similarly effective at improving blood gases and reducing the work of breathing; however, while the addition of EPAP to pressure support ventilation (that is BiPAP) further decreased the work of breathing there was no additive effect on the correction of gases. ${ }^{754}$

These studies indicate that non-invasive ventilation is beneficial to the acute treatment of chronic obstructive airways disease; it reduces the need for intubation and may reduce both hospital length of stay and mortality. Acidosis and hypoxia are more responsive to treatment than hypercarbia and show significant improvement within one hour of treatment.

\section{EVIDENCE FOR USE IN ACUTE PULMONARY}

OEDEMA

There are four randomised controlled trials investigating non-invasive ventilation in acute pulmonary oedema (table 2). Three compare CPAP with standard treatment with high flow oxygen in intensive care settings ${ }^{21-55}$ and one compares BiPAP with CPAP for emergency department treatment of pulmonary oedema. ${ }^{56}$ Wood et al compared BiPAP with standard treatment in patients with various causes of acute respiratory failure in the emergency department. ${ }^{57}$

Although the studies comparing CPAP with standard treatment contain relatively small numbers $(39,40$, and 100 patients, respectively) some benefits are clearly demonstrated. All showed significant improvements with CPAP in subjective respiratory status and blood gas analysis over 30 minutes to six hours and, generally, improvement of various cardiovascular parameters without exacerbation of pre-existing hypotension. There was a decrease in need for endotracheal intubation and mechanical ventilation in all studies (combining study populations: $12 / 89$ (13\%, range 
0\%-30\%) with CPAP, compared with 31/90 (34\%, range $24 \%-60 \%$ ) with standard treatment) but this was not statistically significant in one. ${ }^{28}$ No complications of non-invasive ventilatory therapy were reported.

Medium to long term outcomes were no different in any of the studies comparing CPAP with standard treatment. Bersten et al demonstrated no significant differences in blood gas analysis at 24 hours..$^{55}$ Hospital mortality and length of stay was not significantly different in any of the studies. There was no difference in one year mortality. ${ }^{21}$

The one study comparing CPAP with BiPAP suggested more rapid improvement with BiPAP. ${ }^{56}$ Patients receiving BiPAP had statistically significant improvements in $\mathrm{PaCO}_{2}, \mathrm{pH}$, heart rate, respiratory rate, and dyspnoea scores at 30 minutes but CPAP showed only improvements in respiratory rate. This study was terminated early, with only 27 patients, because of a significantly higher incidence of myocardial infarction in patients receiving BiPAP: $10 / 14$ (71\%) compared with $4 / 13$ (31\%) with CPAP and $38 \%$ in a matched historical control group of 200 . There were no statistically significant differences in baseline characteristics of the two study groups. Whether BiPAP caused the infarcts is unclear. Analysis of creatine kinase $\mathrm{MB}$ fractions suggests that a significant number of the infarctions may have been underway at enrolment. There was no significant difference in time on the device, mortality, or length of stay (intensive care unit and hospital) between the groups.

When BiPAP and standard treatment was compared with standard treatment alone in a heterogeneous group of emergency department patients ${ }^{57}$ (10 with acute pulmonary oedema, six chronic obstructive airways disease, nine pneumonia, one interstitial lung disease, and one sepsis) a trend towards increased hospital mortality (4/16 (25\%) compared with $0 / 11$ ) and number of acquired organ system derangements was found in the group randomised to BiPAP. Those receiving BiPAP tended to improve their mean arterial pressure and $\mathrm{PaO}_{2}$ faster than the control group. The authors suggest that the poorer outcome may be related to predetermined biases on the part of treating physicians and respiratory therapists in favour of non-invasive ventilation (a reluctance to abandon non-invasive ventilation until the last moment). As noted by the authors, the risk of both type one and two errors is increased in a study of this size. Although there was no statistically significant difference between the groups at presentation, a higher number of patients in the treatment group had pneumonia at presentation, $7 / 16$ or $43.8 \%$ compared with $2 / 11$ or $18.2 \%$ of those receiving standard treatment. It is not stated what the presenting diagnosis of the hospital nonsurvivors was but pneumonia has been associated with poorer outcome in patients receiving non-invasive ventilation. ${ }^{45} 52$

Case series studies also support the beneficial effect of $\mathrm{BiPAP}^{40} 45^{47}$ 58-61 and CPAP ${ }^{16}$ 62-64 on pulmonary oedema. The largest of the studies looking at CPAP on acute pulmonary oedema was a retrospective review of 75 patients treated in the emergency department in whom only $4 \%$ required intubation and mean time on CPAP was 1.9 hours. ${ }^{64}$

Overall, the above studies indicate that noninvasive ventilation was effective in decreasing the intubation rate in acute pulmonary oedema and speeds the acute treatment of pulmonary oedema with few complications. ${ }^{65}$ There is no significant improvement in length of stay or long term mortality compared with standard treatment.

\section{EVIDENCE FOR USE IN OTHER RESPIRATORY} DISORDERS

Non-invasive ventilation is widely used in nonacute settings such as home treatment of stable chronic obstructive airways disease, ${ }^{66} 67$ postoperatively, ${ }^{68}{ }^{69}$ and in weaning from conventional mechanical ventilation. ${ }^{67} 70$

Case reports and small case series describe the use of non-invasive ventilation for acute respiratory failure of many aetiologies other than cardiogenic pulmonary oedema and obstructive airways disease. These include pneumonia, ${ }^{4525969}$ pulmonary embolism, ${ }^{52}$ stroke, ${ }^{59}$ overdose, ${ }^{59}$ restrictive lung diseases, ${ }^{20} 7172$ acute respiratory distress syndrome of various aetiologies, ${ }^{69} 7374$ Pneumocystis carinii pneumonia, ${ }^{75}$ Goodpasture's disease, ${ }^{76}$ fat embolism, ${ }^{76}$ bronchiectasis, ${ }^{77}$ mediastinitis, ${ }^{60}$ laryngeal dyspnoea, ${ }^{60}$ and as an option to traditional ventilation in palliative care. ${ }^{78}$

PROBLEMS WITH NON-INVASIVE VENTILATION Non-invasive ventilation appears to be remarkably free of serious complications and side effects. The primary disadvantage of noninvasive ventilation is its reliance on a spontaneously breathing patient who is able to protect their airway against the risk of aspiration. If either of these conditions are not met, endotracheal intubation and traditional ventilation is indicated.

The most commonly reported complications of non-invasive ventilation are nasal bridge skin abrasions $^{29} 31424562747980$ and patient intolerance of the treatment. ${ }^{2952627580}$ Although a possibility with firmly applied masks, skin abrasions are usually only seen in long term use of non-invasive ventilation. Patient intolerance of non-invasive ventilation can be reduced by education before its application (although this is often difficult in an emergency setting) and ongoing explanation and reassurance. Hypoxic and hypercarbic effects on mental state may be in part responsible for this intolerance.

Gastric distension and aspiration is a frequently discussed side effect of non-invasive ventilation, but is relatively rarely described in clinical trials. ${ }^{31458182}$ Studies of the pressure needed to inflate the stomach via non-invasive ventilation suggest that at least $25 \mathrm{~cm} \mathrm{H}_{2} \mathrm{O}$ is required $^{2679}$; this is significantly higher than the levels in general use. Some authors describe the routine placement of nasogastric tubes to prevent gastric distension, ${ }^{62}$ but this is probably unnecessary and can lead to excessive leaks. 
Non-invasive ventilatory systems are, generally, quite tolerant of leaks but mouth leaks with nasal masks can lead to therapeutic failure. ${ }^{41}{ }^{79}$ Oral loss of pressure with nasal ventilation may be prevented by the soft palate being pressed against the tongue to give a seal. ${ }^{26}$ When this is insufficient a chin $\operatorname{strap}^{29}$ may be applied or changing to a facemask ${ }^{56}$ may be indicated.

Case reports exist of other complications of non-invasive ventilation. A variety of arrhythmias (bradycardia, ventricular tachycardia, and ventricular standstill) have been reported during CPAP but were all probably related to underlying myocardial infarction. ${ }^{64}$ Pneumothorax is reported to have complicated treatment of $P$ carinii pneumonia, but these patients are at high risk of this when ventilated by traditional means. ${ }^{83} \mathrm{~A}$ neonate is also reported to have suffered pulmonary venous air embolism while undergoing BiPAP treatment. $^{84}$ These cases serve as an important reminder of the potential for barotrauma with any form of positive pressure ventilation. Pneumocephalus has been described in one patient receiving CPAP after weaning from traditional ventilation who had an unrecognised base of skull fracture as a result of a motor vehicle accident. ${ }^{85}$ One case of bilateral tympanic rupture and otorrhagia is reported in an agitated patient coughing against CPAP. ${ }^{86}$ Subconjunctival emphysema ${ }^{87}$ and corneal abrasions ${ }^{80} 88$ have also been reported; a well fitting mask significantly reduces the risk of both of these.

\section{Conclusions}

Non-invasive ventilation, CPAP and BiPAP, appears to be an effective addition to standard treatment for acute exacerbations of obstructive airways diseases and pulmonary oedema. It seems to be a safe, readily applied modality of ventilatory assistance that decreases the need for endotracheal intubation, speeds recovery, and may shorten hospital length of stay.

Published experience, in the form of large randomised controlled trials, is remarkably limited and uniform recommendations with respect to indications, contraindications, and the exact manner in which non-invasive ventilation should be applied are lacking. Although there are some theoretical advantages of BiPAP over CPAP, there is no clinical evidence that one offers an advantage over the other in the treatment of acute respiratory failure in the emergency department. Further study is required to clarify these points.

Most of the evidence has been derived from intensive care settings. However, this therapy is extremely useful in an emergency department setting as a first line treatment for acute respiratory distress. Early intervention may avoid the risks and complications of endotracheal intubation and shorten or eliminate intensive care or high dependency admissions.

Clinicians should remain vigilant while using non-invasive ventilation as ongoing monitoring and reassessment remains the key to the successful application of this therapy. However, careful utilisation of non-invasive ventilation in appropriately selected patients will opti- mise the outcomes for patients with acute respiratory failure.

\section{Glossary of terms}

Non-invasive ventilation - application of artificial ventilation via nose or facemask (as opposed to invasive ventilation via an endotracheal tube). There are a number of types of non-invasive ventilation, described below, which are differentiated by the way in which pressure is applied to support ventilation.

Positive end expiratory pressure (PEEP) positive alveolar pressure at the end of expiration. May be intrinsic PEEP (iPEEP) due to dynamic hyperinflation (loss of lung compliance causes prolonged expiration, airway closure, and gas trapping in the alveoli) ${ }^{25}$ or externally applied or extrinsic PEEP (ePEEP) caused by CPAP or the EPAP component of BiPAP.

Continuous positive airway pressure (CPAP) a single level of positive pressure is applied continuously throughout the whole respiratory cycle. ${ }^{89}$

Bilevel positive airway pressure (BiPAP) a system of ventilation in which two levels of airway pressure are applied: expiratory positive airway pressure (EPAP) and inspiratory positive airway pressure (IPAP). The lower pressure, EPAP, is applied during expiration. When the patient makes an inspiratory effort the device senses a small drop in pressure that triggers a flow of gas at the higher IPAP. ${ }^{89}$

Pressure support ventilation - the difference between the inspiratory and expiratory airway pressures, that is, amount of extra "help" the patient is receiving during inspiration. ${ }^{89}$ There is no pressure support ventilation during CPAP. Pressure support ventilation can be given alone, without CPAP or PEEP, in which case end expiratory pressure is atmospheric.

Chronic obstructive airways disease (COAD) also called chronic obstructive lung or pulmonary disease (COLD, COPD) - a condition in which there is chronic obstruction to airflow due to chronic bronchitis and/or emphysema. ${ }^{90}$ Adult asthma, caused by bronchial hyper-reactivity, ${ }^{91}$ is included in obstructive airways disease (OAD) group for the purposes of this review.

Acute pulmonary oedema - an increase in pulmonary venous pressure, most commonly caused by left ventricular failure, causing an accumulation of liquid in the tissue and airways of the lungs. ${ }^{92}$

I would like to thank Associate Professor Peter Cameron and Dr Dominica Zentner for their critical comments during manuscript preparation.

Conflict of interest: none.

Funding: none.

1 Poulton PE. Left-sided heart failure with pulmonary oedema: its treatment with the "pulmonary plus pressure machine". Lancet 1936;231:981-3. 
2 Petty T. A historical perspective of mechanical ventilation. Crit Care Clin 1990;6:489-504.

3 Meyer TJ, Hill NS. Noninvasive positive pressure ventilation to treat respiratory failure. Ann Intern Med 1994;120 760-70.

4 Duncan AW, Oh TE, Hillman DR. PEEP and CPAP. Anaesth Intensive Care 1986;14:236-49.

5 Katz JA, Marks JD. Inspiratory work with and without continuous positive airway pressure in patients with acute respiratory failure. Anesthesiology 1985;63:598-607.

6 Dottorini M, Baglioni S, Eslami A, et al. N-CPAP in patients with COPD in acute respiratory failure. Chest 1995;107: 585-7.

7 Appendini L, Patessio A, Zanaboni S, et al. Physiologic effects of positive end-expiratory pressure and mask pressure support during exacerbations of chronic obstructive pulmonary disease. Am $\mathcal{f}$ Respir Crit Care Med tive pulmonary dise

8 Rossi A, Brandolese R, Milic-Emil J, et al. The role of PEEP in patients with chronic obstructive pulmonary disease in patients with chronic obstructive pulmonary dise

9 Sacchetti AD, Harris RH. Acute cardiogenic pulmonary edema: what's the latest in emergency treatment? Postgrad Med 1988;103:145-7.

10 Abou-Shala N, Meduri U. Noninvasive mechanical ventilation in patients with acute respiratory failure. Crit Care Med 1996;24:705-15.

11 Clark HE, Wilcox PG. Noninvasive positive pressure ventilation in acute respiratory failure of chronic obstructive pulmonary disease. Lung 1997;175:143-54.

12 Pinsky MR, Summer WR. Cardiac augmentation by phasic high in

13 Buda AJ, Pinsky MR, Ingels NB Jr, et al. Effect of intrathoracic pressure on left ventricular performance. $N$ Engl $f$ racic pressure on left

14 Potkin RT, Hudson LD, Veaver LHJ, et al. Effect of positive end-expiratory pressure on right and left ventricular function in patients with the adult respiratory distress syndrome. Am Rev Respir Dis 1987;135:307-11.

15 Calvin JE, Driedger AA, Sibbald WJ. Positive endexpiratory pressure (PEEP) does not depress left ventricular function in patients with pulmonary edema. Am Rev Respir Dis 1981;124:121-8.

16 Räsänen J, Väisän J, Heikkilä J, et al. Acute myocardial infarction complicated by left ventricular dysfunction and respiratory failure: the effects of continuous positive airway pressure. Chest 1985;87:158-62.

17 Väisänen IT, Räsänen J. Continuous positive airway pressure and supplemental oxygen in the treatment of cardiogenic pulmonary oedema. Chest 1987;92:481-5.

18 Apuzzo MLJ, Weiss MH, Petersons V, et al. Effect of positive end-expiratory pressure ventilation on intracranial pressure end-expiratory pressure ventilation on

19 Goldberg P, Reissmann H, Maltais F, et al. Efficacy of noninvasive CPAP in COPD with acute respiratory failure. Eur Respir f 1995;8:1894-900.

20 Criner G, Travaline JM, Brennan KJ, et al. Efficacy for a full face mask for noninvasive positive pressure ventilation. Chest 1994;106:1109-15

21 Lin M, Yang YF, Chiang HT, et al. Reappraisal of continuous positive airway pressure therapy in acute cardiogenic pulmonary edema: short-term results and long-term follow-up. Chest 1995;107:1379-86.

22 Bott J, Carroll MP, Conway JH, et al. Randomised controlled trial of nasal ventilation in acute ventilatory failure due to chronic obstructive airways disease. Lancet 1993;341: 1555-7.

23 American Thoracic Society. Standards for the diagnosis and care of patients with chronic obstructive pulmonary disease
(COPD) and asthma. Am Rev Respir Dis 1987;136:225-44

24 Smith TC, Marini JJ. Impact of PEEP on lung mechanics and work of breathing in severe airflow obstruction. $f A p p l$ Physiol 1988;65:1488-99.

25 Van den Berg B, Aerts JG, Bogaard JM. Effect of continuous positive airway pressure (CPAP) in patients with chronic obstructive pulmonary disease (COPD) depending on intrinsic PEEP levels. Acta Anaesthesiol Scand 1995;39: 1097-102.

26 Hillberg RE, Johnson DC. Noninvasive ventilation. $N$ Engl f Med 1997;337:1746-51.

27 Diaz O, Iglesia $R$, Ferrer $M$, et al. Effects of noninvasive ventilation on pulmonary gas exchange and hemodynamics during acute hypercapnic exacerbations of chronic obstructive pulmonary disease. Am 7 Respir Crit Care Med tive pulmonary

28 Räsänen J, Heikkilä J, Downs J, et al. Continuous positive airway pressure by face mask in acute cardiogenic pulmonary edema. Am F Cardiol 1985;55:296-300.

29 Kramer N, Meyer TJ, Meharg J, et al. Randomised, prospective trial of noninvasive positive pressure ventilation in acute respiratory failure. Am $\mathcal{F}$ Respir Crit Care Med 1995;151:1799-806.

30 Brochard L, Mancebo J, Wysocki M, et al. Noninvasive ventilation for acute exacerbations of chronic obstructive pulmonary disease. N Engl f Med 1995;333:817-22.

31 Celikel T, Sungur M, Ceyhan B, et al. Comparison of noninvasive positive pressure ventilation with standard medical therapy in hypercapnic acute respiratory failure. Chest 1998;114:1636-42.

32 Martin JG, Shore S, Engel LA. Effect of continuous positive airway pressure on lung mechanics and pattern of
breathing in induced asthma. Am Rev Respir Dis 1982;126: breathing $812-7$.
33 Shivaram U, Miro AM, Cash ME, et al. Cardiopulmonary responses to continuous positive airway pressure in acute asthma. 7 Crit Care 1993;8:87-92.

34 De Lucas P, Tarancón C, Puente L, et al. Nasal continuous positive airway pressure in patients with COPD in acute respiratory failure. Chest 1993;104:1694-7.

35 Miro AM, Shivaram U, Hertig I. Continuous positive airway pressure in COPD patients in acute hypercapnic respiratory failure. Chest 1993;103:266-8.

36 Qvist J, Anderson JB, Pemberton M, et al. High-level PEEP in severe asthma. N Engl F Med 1982;307:1347-8.

$37 \mathrm{Lim}$ TK. Treatment of severe exacerbation of chronic obstructive pulmonary disease with mask-applied continuous positive airway pressure. Respirology 1996;1:189-93.

38 Mansel JK, Stogner SW, Norman JR. Face-mask CPAP and sodium bicarbonate infusion in acute, severe asthma and metabolic acidosis. Chest 1989;96:943-4.

39 Meduri GU, Cook TR, Turner RE, et al. Noninvasive positive pressure ventilation in status asthmaticus. Chest 1996; 110:767-74

40 Teba L, Marks P, Benzo R. Non-invasive mechanical: the benefits of the BiPAP system. $W V$ Med $\mathcal{F} 1996$;92:18-21.

41 Soo Hoo GW, Santiago S, Williams AJ. Nasal mechanical ventilation for hypercapnic respiratory failure in chronic obstructive pulmonary disease: determinants of success and failure. Crit Care Med 1994;22:1253-61.

42 Wysocki M, Tric L, Wolff MA, et al. Noninvasive pressure support ventilation in patients with acute respiratory
failure. Chest 1993;103:907-13.

43 Ambrosino N, Foglio K, Rubini F, et al. Non-invasive ventilation in acute respiratory failure due to chronic obstructive pulmonary disease: correlates for success. Thorax 1995;50: $755-7$.

44 Fernandez R, Blanch L, Valles J, et al. Pressure support ventilation via face mask in acute respiratory failure in hypercapnic COPD patients. Intensive Care Medicine 1993;19: 456-61.

45 Meduri GU, Turner RE, Abou-Shala N, et al. Noninvasive positive pressure ventilation via face mask; first-line intervention in patients with acute hypercapnic and hypoxintervention in patients with acute hypercapnic and

46 Confalonieri M, Aiolfi S, Gandola L, et al. Severe exacerbation of chronic obstructive lung disease treated with BiPAP by nasal mask. Respiration 1994;61:310-6.

77 Poponick JM, Renston JP, Emerman CL. Successful use of nasal BiPAP in three patients previously requiring intubation and mechanical ventilation. F Emerg Med 1997;15: $785-8$.

48 Hilbert G, Gruson D, Gbikpi-Benissan G, et al. Sequential use of noninvasive pressure support ventilation for acute exacerbations of COAD. Intensive Care Medicine 1997;23. 955-61.

49 Ong KC, A'Court GD, Eng P, et al. Noninvasive positive-pressure ventilation for acute respiratory failure in medical intensive care unit in Singapore. Ann Acad Med Singapore 1996;25:791-6.

50 Pollack CV Jr, Fleisch KB, Dowsey K. Treatment of acute bronchospasm with beta-adrenergic agonist aerosols delivered by a nasal bilevel positive airway pressure circuit. Ann Emerg Med 1995;26:552-7.

51 Nava S, Ambrosino N, Bruschi C, et al. Physiological effects of flow and pressure triggering during non-invasive mechanical ventilation in patients with chronic obstructive pulmonary disease. Thorax 1997;52:249-54.

52 Vitacca M, Clini E, Rubini F, et al. Non-invasive mechanical ventilation in severe chronic obstructive lung disease and acute respiratory failure: short- and long-term prognosis. acute respiratory failure: short- and lon
Intensive Care Medicine 1996;22:94-100.

53 Corbetta L, Ballerin L, Putinati S, et al. Efficacy of noninvasive positive pressure ventilation by facial and nasal mask in hypercapnic acute respiratory failure: experience in a respiratory ward under usual care. Monaldi Arch Chest Dis 1997; 52:421-8

54 Meecham-Jones DJ, Paul EA, Grahame-Clarke C, et al. Nasal ventilation in acute exacerbations of chronic obstructive pulmonary disease: effect of ventilator mode on arterial blood gas tensions. Thorax 1994;49:1222-4.

55 Bersten AD, Holt AW, Vedig AE, et al. Treatment of severe cardiogenic pulmonary edema with continuous positive airway pressure delive

56 Mehta S, Jay GD, Woolard RH, et al. Randomized, prospective trial of bilevel versus continuous positive airway pressure in acute pulmonary edema. Crit Care Med 1997;25:620-8.

57 Wood KA, Lewis L, Von Harz B, et al. The use of noninvasive positive pressure ventilation in the emergency department; results of a randomized clinical trial. Chest 1998;113:1339-46.

58 Lo Coco A, Vitale G, Marchese S, et al. Treatment of acute respiratory failure secondary to pulmonary oedema with bi-level positive airway pressure by nasal mask. Monaldi Arch Chest Dis 1997;52:444-6.

59 Pollack C Jr, Torres MT, Alexander L. Feasibility study of the use of bilevel positive airway pressure for respiratory support in the emergency department. Ann Emerg Med 1996;27:189-92.

60 Wysocki M, Tric L, Mazeyrac C, et al. Noninvasive pressure support ventilation (NIPSV) in acute respiratory failure. Am Rev Respir Dis 1992:145. A527.

61 Polkey MI, Moxham J. Noninvasive ventilation in the management of decompensated COPD. Monaldi Arch Chest Dis 1995;50:378-82. 
62 Meduri GU, Conoscenti CC, Menashe P, et al. Noninvasive facemask ventilation in patients with acute respiratory failfacemask ventilation in patient
ure. Chest 1989;95:865-70.

63 Shivaram U, Donath J, Khan F, et al. Effects of continuous positive airway pressure in acute asthma. Respiration 1987; 52:157-62

64 Kelly AM, Georgakas C, Bau S, et al. Experience with the use of continuous positive airway pressure (CPAP) therapy in the emergency management of acute severe pulmonary oedema. Aust NZ F Med 1997;27:319-22.

65 Pang D, Keenan SP, Cook DJ, et al. The effect of positive pressure airway support on mortality and the need for intu-
bation in cardiogenic pulmonary edema: a systemic review. Chest 1998;114:1185-92.

66 Hill NS. Noninvasive ventilation: does it work, for whom, and how? Am Rev Respir Dis 1993;147:1050-5.

67 Nicholson D, Tiep B, Jones R, et al. Noninvasive positive-pressure ventilation in chronic obstructive pulmo4:66-75.

68 Pennock BE, Crawshaw L, Kaplan PD. Noninvasive nasal mask ventilation for acute respiratory failure: institution of a new therapeutic technology for routine use. Chest

69 Pennock BE, Kaplan, PD, Carlin BW, et al. Pressure support ventilation with a simplified ventilatory support system administered with a nasal mask in patients with respiratory failure. Chest 1991;100:1371-82.

70 Hormann C, Baum M, Putensen C, et al. Biphasic positive airway pressure (BiPAP) - a new mode of ventilatory support. Eur f Anaesthesiol 1994;11:37-42.

71 Chevrolet JC, Jolliet P, Abajo B, et al. Nasal positive pressure ventilation in patients with acute respiratory failure: difficult and time-consuming procedure for nurses. Chest 1991;100:775-82.

72 Servera E, Perez M, Marin J, et al. Nonivasive nasal mask ventilation beyond the ICU for an exacerbation of chronic respiratory insufficiency. Chest 1995;108:1572-6.

73 Ranieri VM, Dambrosio M, Brienza N. Intrinsic PEEP and cardiopulmonary interaction in patients with COPD and cardiopulmonary interaction in patients with COPD

74 Covelli HD, Weled BJ, Beekman JF. Efficacy of continuous positive airway pressure administered by face mask. Chest $1982 ; 81: 147-50$

75 Criner G, Travaline JM, Brennan KJ, et al. Efficacy for a ful face mask for noninvasive positive pressure ventilation. Chest 1994;106:1109-15.

76 Hoff BH, Fleming DC, Sasse F. Use of positive airway pressure without endotracheal intubation. Crit Care Med 1979; 7:559-61.

77 Fiorenzano G, Marruchella A, Aufiero A, et al. Pulmonary edema and acute hypercapnic respiratory failure treated with bi-level nasal-CPAP: case report. Panminerva Med 1997;39:53-5.
78 Ayres BM, Kozam RL, Lukas DS. The effects of intermittent positive pressure breathing on intrathoracic
pressure, pulmonary mechanics and the work of breathing. pressure, pulmonary mechanics and

79 Brochard L, Isabey D, Piquet J, et al. Reversal of acute exacerbations of chronic obstructive lung disease by inspiratory assistance with a face mask. N Engl F Med 1990;323:152330.

80 Benhamou D, Girault C, Faure C, et al. Nasal mask ventilation in acute respiratory failure: experience in elderly patients. Chest 1992;102:912-7.

81 Meduri GU, Abou-Shala N, Fox RC, et al. Noninvasive face mask mechanical ventilation in patients with acute hypercapnic respiratory failure. Chest 1991;100:445-54

82 Vitacca M, Rutini F, Foglio K, et al. Non-invasive modalities of positive pressure ventilation improved the outcome of acute exacerbations in COLD patients. Intensive Care Medicine 1993:19:450-5.

83 Sheehan GJ, Miedzinski LJ, Schroeder DG. Pneumothorax complicating BiPAP therapy for Pneumocystis carinii pneumonia. Chest 1993;103:1310.

84 Weiner JH, Kliegman RM, Farnaroff AA, et al. Pulmonary venous air embolism in the neonate. Crit Care Med 1986;14:67-9.

85 Klopfenstein CE, Forster A, Suter PM. Pneumocephalus; a complication of continuous positive airway pressure after trauma. Chest 1980;78:656-7.

86 Weaver LK, Fairfax WR, Greenway L. Bilateral otorrhagia associated with continuous positive airway pressure. Chest 1988;93:878-9.

87 Lee TS, Schrader MW, Wright BD. Subconjunctival emphysema as a complication of PEEP. Ann Ophthalmol 1980;129:1080-1.

88 Cole GF, Chandhuri PR, Carroll LP. Mask for continuous positive airway pressure; does it cause corneal abrasions? BMF 1982;284:19.

89 Tan IKS, Oh TE. Mechanical ventilatory support. In: Oh $\mathrm{TE}$, ed. Intensive care manual. Oxford: ButterworthHeinemann, 1997: 246-55.

90 Honig EG, Ingram RH. Chronic bronchitis, emphysema and airways obstruction. In: Fauci AS, Braunwald E, Isselbacher KJ, et al, eds. Harrison's principles of internal bacher KJ, et al, eds. Harrison's principles of internal
medicine. 14th Ed. New York: McGraw-Hill, 1998;145160 .

91 McFadden ER. Asthma. In: Fauci AS, Braunwald E, Isselbacher KJ, et al, eds. Harrison's principles of internal medicine. 14th Ed. New York: McGraw-Hill, 1998: 1419-26.

92 Ingram RH, Braunwald E. Dyspnea and pulmonary edema. In: Fauci AS, Braunwald E, Isselbacher KJ, et al, eds. Harrison's principles of internal medicine. 14th Ed. New York: McGraw-Hill, 1998: 190-4. 